\title{
Collaborative Information Integration for Construction Safety
} Monitoring

\author{
Qingwen Xu' ${ }^{1}$; Heap-Yih Chong²; Pin-Chao Liao ${ }^{3 *}$ \\ ${ }^{1}$ Graduate Research Assistant, Dept. of Construction Management, Tsinghua University, China. E-mail: \\ xqw0521@163.com) \\ ${ }^{2}$ Senior Lecturer, School of Design and the Built Environment, Curtin University, GPO Box U1987, Perth, \\ WA 6845, Australia. E-mail: heap-yih.chong@curtin.edu.au \\ ${ }^{3}$ Associate Professor, Dept. of Construction Management, Tsinghua University, China (Corresponding Author, \\ E-mail: pinchao@tsinghua.edu.cn)
}

\begin{abstract}
Safety monitoring is a critical component of safety management. However, asymmetric safety information and inefficient communication between various stakeholders currently limit the effectiveness of safety monitoring in the construction industry. The aim of this study is to develop a holistic and collaborative information integration framework for safety monitoring that collects, analyzes, and disseminates safety information. The proposed framework provides an interconnecting platform for stakeholder communication consisting of five layers for safety monitoring: preparation layer, monitoring layer, integration layer, reporting layer, and intervention layer. To evaluate the proposed framework, a prototype system was developed and tested as a case study for building projects in Qingdao, China. The results indicate that the proposed framework and prototype were embraced by the stakeholders in the city and contributed to an improved collaborative working environment for safety inspection and monitoring in construction projects.
\end{abstract}

Keywords: Collaborative information sharing; information asymmetry; safety inspection; real-time monitoring; framework; prototype

\section{Introduction}

Safety management has long been a subject of intense discussion. When developed in accordance with standard guidelines, like OHSAS 18002:2008 [1], and mandatory regulations, including the Construction Project Safety Production Management 
Regulations [2] in China, the ideal safety management system includes a complex relationship between multiple stakeholders. A properly designed platform for safety management can facilitate efficient information communication between multiple stakeholders, promoting the adoption of a more effective safety management system. Safety inspection is the common factor shared by many different safety management strategies. By relying on an output checklist generated by the safety planning procedure, inspection results have been found to enable a more effective safety management review and led to an improvement in safety [3]. However, traditional on-site safety inspection is conducted manually, resulting in significant inefficiency and ineffectiveness of the "collection, analysis, and dissemination" procedure of site safety information communication [4]. A conventional inspection procedure often begins with a paper-based checklist and ends with a simple inspection report that includes followup instructions. This can result in the generation of large quantities of subjective and fragmented data $[4,5]$. Furthermore, this manual inspection working mode has inherent problems because it relies heavily on the perceptual and cognitive capabilities of the observer [6, 7]. As a result, the information dissemination process becomes notably inefficient and error-prone.

Conventionally, government can serve as an effective external supervision system through the intensity [8] and capacity [9] of its policy implementation. However, a high degree of effectiveness seems impossible in current construction practices considering the shortage of specialized inspectors in government departments and the cost incurred for frequent inspections [10]. Government officials or any third-party agencies are unable to monitor a construction site at all time a site at all time [11]. Various managerial and technological approaches have attempted to address the information asymmetry problem in construction safety management. Previous studies on managerial approaches have focused on designing the contract [12] or procurement system [13], defining third-party roles [14-16], providing adequate incentives and penalties [17], and so on. Studies on technological approaches have mainly concentrated on adopting or developing advanced technologies to improve the efficiency and accuracy of human inspection through smartphones [18], virtual reality (VR) safety training [19], the iObserver inspection tool [3], the use of Internet of Things (IoT) for safety monitoring [20-26], and so on. Yet, the synergy between the managerial and technological approaches is still lacking from the perspective of information asymmetry, particularly in collaborating multiple stakeholders for construction safety inspection and monitoring. 
Therefore, the current study aims to develop a collaborative information integration framework that collects, analyzes, and disseminates safety information to project stakeholders in the construction industry. The framework was implemented in a prototype system that was demonstrated on a series of construction sites in Qingdao, China. This selection was due to strong support from the local government and the presence of complex stakeholder relationships in the local industry. Furthermore, a local insurance company was contacted and involved in the framework development and prototype testing to address a perceived gap in construction safety management research from the third party perspective [14]. The remainder of this paper is organized as follows. First, previous research related to the problems of construction site safety inspection is reviewed, and the latest developments in the use of information technology to address these problems are discussed. Next, the main methodological approaches for the framework are defined. Then, the proposed framework and monitoring platform, consisting of two information modules and five functional layers, is presented. Then, the prototype system is demonstrated as a case study. The implementation outcomes are discussed for their practical implications and theoretical contributions. The final section summarizes the conclusions of the research, limitations and recommendations for future studies.

\section{Theoretical foundation and existing research gaps}

\subsection{The need for an effective safety inspection and monitoring system}

Information asymmetry is a common problem recognized to be detrimental to the effectiveness of site safety management [27]. Focus on organizational and management issues, previous studies have investigated the principal-agent problem based on the asymmetric information phenomenon in the construction industry, in which the relationships between the owners, contractors, and other stakeholders are complex and lack long-term cooperation [28]. Information asymmetry issues can exist between any two stakeholders in a construction project. For example, in both the bidding and construction phases, contractors and supervisors have information superiority over the owners regarding their own qualifications and implementation efforts [29-31]. Compared to insurance companies and government departments, contractors and supervisors are also better informed about the key characteristics and risk statuses of the projects [32]. The common objective of all involved parties to maximize their own economic interests, and any rent-seeking behavior appearing from collusion between 
two parties, may disrupt the efficiency of safety management [13]. For government departments, the information asymmetry problem is particularly severe. On one hand, due to their public accountability and performance requirements, government departments must monitor the project safety information. However, these departments regularly suffer from insufficient reliable information due to a lack of professional inspectors to conduct on-site inspections $[10,11]$. On the other hand, because the thirdparty safety inspection market is not well-developed, government departments must provide most external supervision, which conflicts with the perceived need of construction companies to conceal safety information from government inspectors for fear of administrative penalties or damage to their corporate image. In this case, government departments are forced to strengthen the intensity and frequency of supervision to discover more information regarding project safety, exacerbating issues associated with the limited manpower available for traditional supervision. This can lead construction companies to focus more on concealing safety issues, creating a feedback loop of asymmetric information. Asymmetric safety information between stakeholders has a significant negative impact on project safety management, in that, managers cannot effectively manage with insufficient safety information or with only the isolated information available to a particular stakeholder. At the industry level, information asymmetry can result in moral hazards and adverse selection [12, 33], increasing the risk exposure of the entire construction industry.

Another phenomenon of information asymmetry is that insurance company participation has been lacking based on an evaluation of construction safety monitoring systems [14]. As one of the major risk transfer options, construction insurance should be used to cover specific construction projects as an integral part of whole-process risk management. However, this is not an easy goal to achieve due to several external and internal constraints. First, most insurance companies merely engage in the claim settlement procedure after an accident has occurred; they have no apparent incentive to participate in construction risk management or supervision [34, 35]. Therefore, very few insurance companies can provide practical advice or assistance in construction management processes because they do not staff sufficient qualified specialists in this field. In addition to these professional issues, insurance products are also currently facing an unfavorable market environment. Contractors' all risks (CAR) and erection all risks (EAR) policies, which have been proven to be helpful tools in protecting the interests of both clients and contractors, are not mandatory in some countries, such as 
China and Tanzania [36]. Accordingly, there remains a gap between the construction monitoring system and the insurance mechanism [14], in which insurance companies cannot determine the credit status or the construction performance of the relevant parties, particularly the owners and contractors, and cannot effectively set an appropriate premium rate for the associated construction risks [34]. Nevertheless, insurance companies have a strong motivation to maintain construction safety because increased safety reduces their own operating costs. As a result, insurance companies are actively seeking ways to mitigate information asymmetry in the construction market and to expand their services in the area of project risk management.

From the above research, it can be concluded that defects in current safety management mechanisms include information asymmetry, inefficiency of information dissemination, and other issues. To address safety supervision issues, previous studies have argued that a well-designed contract [12], information management promotion [27], and adequate incentives and penalties [17] could be good solutions. Some researchers have advocated new participation modes, such as integrated project delivery (IPD) [13] to ease these problems. With respect to government administration, approaches such as introducing professional third-party agencies [14-16] and establishing a high-performance information system [30] have been proposed to strengthen the effectiveness of safety management. Regarding insurance, previous studies have placed their focus on two main topics: the ratemaking method and policy proposals. For example, it has been stated that the insurance rate should be adjusted according to the safety performance of the contractor [35], and several ratemaking methods have been proposed [37, 38]. However, the ability to make an accurate calculation is dependent upon reliable data, a limitation that none of these previous studies have identified. Furthermore, limited studies have investigated comprehensive mechanisms for eliminating these deficiencies in a thorough manner. As a result of the limitations of previous research, the objective of the current study was to develop a collaborative framework to address the above-mentioned problems from a holistic perspective, and to propose a feasible way to maximize insurance services in the construction risk management field.

\subsection{Information technology applications for integrated monitoring systems}

Building a high-performance information system is a commonly recognized approach for addressing information asymmetry problems [39, 40] and promoting 
construction safety management. Several information technology applications have been widely used to enhance the effectiveness of safety inspection. As the application of computer technology to image analysis in the construction industry has yet to mature, manual inspection is likely to remain very common in the industry for some time. Therefore, any applications developed to date mainly attempt to improve the efficiency and accuracy of human safety inspection and follow-up. For example, to complement the traditional paper-based safety inspection and report process, Sunkara [41]developed the Hazard Prevention Tool (HPT), a tablet app that recorded pictures of the construction site, provided the ability to mark hazardous areas on the pictures, and generated the inspection reports containing corresponding recommended solutions. To streamline the inspection process, as well as information records, Kang et al. [42] presented an innovative site inspection tool kit on an iPad that provided an automated site inspection template. Similarly, the iObserver iPad application was developed to provide step-by-step guidance to facilitate a more effective inspection practice, displaying a list of safety requirements associated with each specific work task [3]. Other portable tools have also combined smartphones with IoT to improve the efficiency of information recording during safety inspection [18].

A more advanced information technology application is to collect safety-related data automatically. The automatic monitoring of structures under construction is wellsuited to foundation pit engineering, tunnel engineering, and bridge engineering. Besides, many efforts have been made to realize automatic monitoring and warning for human-related tasks and construction hazards. Sensing and positioning systems based on ultra wide band (UWB), Bluetooth Low Energy (BLE), Radio Frequency Identification (RFID), and ZigBee have been developed to monitor the dynamic spatial relationships among workers, equipment, structures, and materials on construction site, so as to realize real-time monitoring and alerting of workers approaching hazardous areas and cross-operations [22-26]. Moreover, pressure sensors, RFID devices, vision cameras and other positioning technologies were also utilized to check the PPE compliance before or after entering the specific construction area [43, 44]. The development of sensing technology and the IoT is redefining the entire outlook of the construction industry with respect to monitoring [20], and more research has been devoted to investigating the possibilities of automatic safety data collection on a larger scale. Zhou and Ding [21] established a hazard energy monitoring system using IoTbased devices to continuously track the time and space characteristics of hazard energy, 
providing real-time monitoring and early warning on the construction site. Computer vision techniques have also been extended to construction safety and health monitoring to provide object detection, object tracking, and action recognition $[45,46]$. Starbuck et al. [47] developed a method for on-site recording and kinematic modeling of construction worker tasks using stereo cameras. Escorcia et al. [48] proposed an algorithm to recognize construction workers and their actions Microsoft Kinect sensors. Notably, the characteristics of real-time management provided by Building Information Modelling are in perfect compliance with the needs of safety monitoring, enabling easy integration $[49,50]$.

As summarized in Table 1, the technological applications for safety management have utilized various technologies and tools to cope with different purposes of safety monitoring, however there are still rooms for improvement. First, the data sources of the previous studies were either manual inspection or automatic recording, which could not cover all the possible types of hazards of construction projects alone. Next, the previous studies primarily focused on real-time data collection and warning, but hardly considered the functions of management assessment, which these platforms were limited to the activity-level safety management. Besides, the information output was limited to description reports or statistical results even at the project level. Furthermore, the proposed means of safety inspection were intended to provide assistance for contractors or project managers, neglecting the ability of information systems to serve as a powerful tool in realizing an integral safety supervision system. Considering the complex network of stakeholders in construction projects, it is important to take into account the different management requirements of different stakeholders like owners and government departments. In this paper, we focus on the information collection and communication needs among multiple stakeholders, integrating both the manual safety inspection results and automatic records to achieve comprehensive safety evaluation, and also to present the safety reports at different levels. 


\begin{tabular}{|c|c|c|c|c|c|}
\hline & Management tools & Data collection & Information output & Management level & Involved stakeholder \\
\hline Sunkara [41] & $\begin{array}{l}\text { Hazard-specific checklists } \\
\text { Corrective recommendations } \\
\text { Portable devices }\end{array}$ & Manual inspection & Description report & $\begin{array}{l}\text { Activity level } \\
\text { Project level }\end{array}$ & $\begin{array}{l}\text { Contractors } \\
\text { Subcontractors } \\
\text { Suppliers }\end{array}$ \\
\hline Zhang et al. [3] & $\begin{array}{c}\text { Task-specific checklists } \\
\text { Corrective actions } \\
\text { Portable devices }\end{array}$ & Manual inspection & Description report & $\begin{array}{l}\text { Activity level } \\
\text { Project level }\end{array}$ & $\begin{array}{c}\text { Contractors } \\
\text { Subcontractors }\end{array}$ \\
\hline Lin et al. [18] & $\begin{array}{c}\text { Portable devices } \\
\text { High Frequency RFID tags }\end{array}$ & Manual inspection & Inspection records & Activity level & $\begin{array}{c}\text { Owners } \\
\text { Contractors }\end{array}$ \\
\hline Lin et al. [51] & Hierarchical checklists & Manual inspection & $\begin{array}{l}\text { Description report } \\
\text { Statistical results }\end{array}$ & $\begin{array}{l}\text { Activity level } \\
\text { Project level }\end{array}$ & $\begin{array}{c}\text { Contractors } \\
\text { Subcontractors }\end{array}$ \\
\hline Ding et al. [52] & $\begin{array}{l}\text { Sensor system } \\
\text { RFID devices }\end{array}$ & Automatic recording & $\begin{array}{l}\text { Raw data } \\
\text { Real-time warning }\end{array}$ & $\begin{array}{l}\text { Activity level } \\
\text { Project level }\end{array}$ & Contractors \\
\hline Dong et al. [44] & $\begin{array}{c}\text { Vision cameras } \\
\text { Pressure sensors } \\
\text { Positioning technologies }\end{array}$ & Automatic recording & $\begin{array}{l}\text { Raw data } \\
\text { Real-time warning } \\
\text { State visualization }\end{array}$ & $\begin{array}{l}\text { Activity level } \\
\text { Project level }\end{array}$ & $\begin{array}{c}\text { Contractors } \\
\text { Subcontractors }\end{array}$ \\
\hline Carbonari et al. [22] & $\begin{array}{l}\text { UWB-based positioning } \\
\text { system }\end{array}$ & Automatic recording & $\begin{array}{l}\text { Real-time warning } \\
\text { State visualization }\end{array}$ & Activity level & Contractors/Unclear \\
\hline Park et al. [23] & BLE-based sensing system & Automatic recording & Real-time warning & Activity level & Contractors/Unclear \\
\hline
\end{tabular}




\begin{tabular}{|c|c|c|c|c|c|}
\hline Costin et al. [24] & RFID devices & Automatic recording & $\begin{array}{c}\text { Raw data } \\
\text { Statistical results }\end{array}$ & $\begin{array}{l}\text { Activity level } \\
\text { Project level }\end{array}$ & Contractors \\
\hline Lee et al. [25] & Mobile sensing devices & Automatic recording & $\begin{array}{l}\text { Inspection records } \\
\text { Real-time warning }\end{array}$ & Activity level & Contractors/Unclear \\
\hline Kelm et al. [43] & RFID devices & Automatic recording & $\begin{array}{l}\text { Inspection records } \\
\text { Statistical results }\end{array}$ & $\begin{array}{c}\text { Activity level } \\
\text { Project level }\end{array}$ & Unclear \\
\hline Naticchia et al. [26] & ZigBee-based sensing system & Automatic recording & $\begin{array}{c}\text { Site state } \\
\text { visualization } \\
\text { Real-time warning }\end{array}$ & $\begin{array}{l}\text { Activity level } \\
\text { Project level }\end{array}$ & Contractors/Unclear \\
\hline
\end{tabular}




\section{Development of the collaborative information integration framework}

In order to enable more effective stakeholder participation, an ideal safety monitoring system should be equipped with powerful management tools as well as an efficient information communication method to generate informative output based on the collected data. To make clear these requirements, interviews were conducted with construction practitioners from the general contractors, government, and service provider. These interviews helped to provide a better understanding of the problems and needs in current practice. It also helped to clarify the cooperation modes between different stakeholders, and determine the detailed functionalities of the monitoring platform. With the assistance of the service provider, a collaborative safety monitoring platform was developed that integrates two information modules and five functional layers.

The collaborative information integration framework of the proposed safety monitoring system is designed to be an interconnected platform including all parties in improving safety performance in construction projects. In consideration of their role in a traditional safety management system, insurance companies or insurance brokerage companies are introduced here to serve as third-party service providers. In this framework, they are responsible for the operation of the proposed framework in the form of the safety information platform, and also provide services to assist project safety management through a group of safety practitioners. The objective of this framework is to link the safety management strategy of each general contractor who has bought into the service, and to create an intimate relationship with the local government. To address the functional defects of previously proposed platforms, the current framework is composed of five layers of safety monitoring processes: preparation layer, monitoring layer, integration layer, reporting layer, and intervention layer (Fig. 1), discussed in Sections 3.1 to 3.5. 

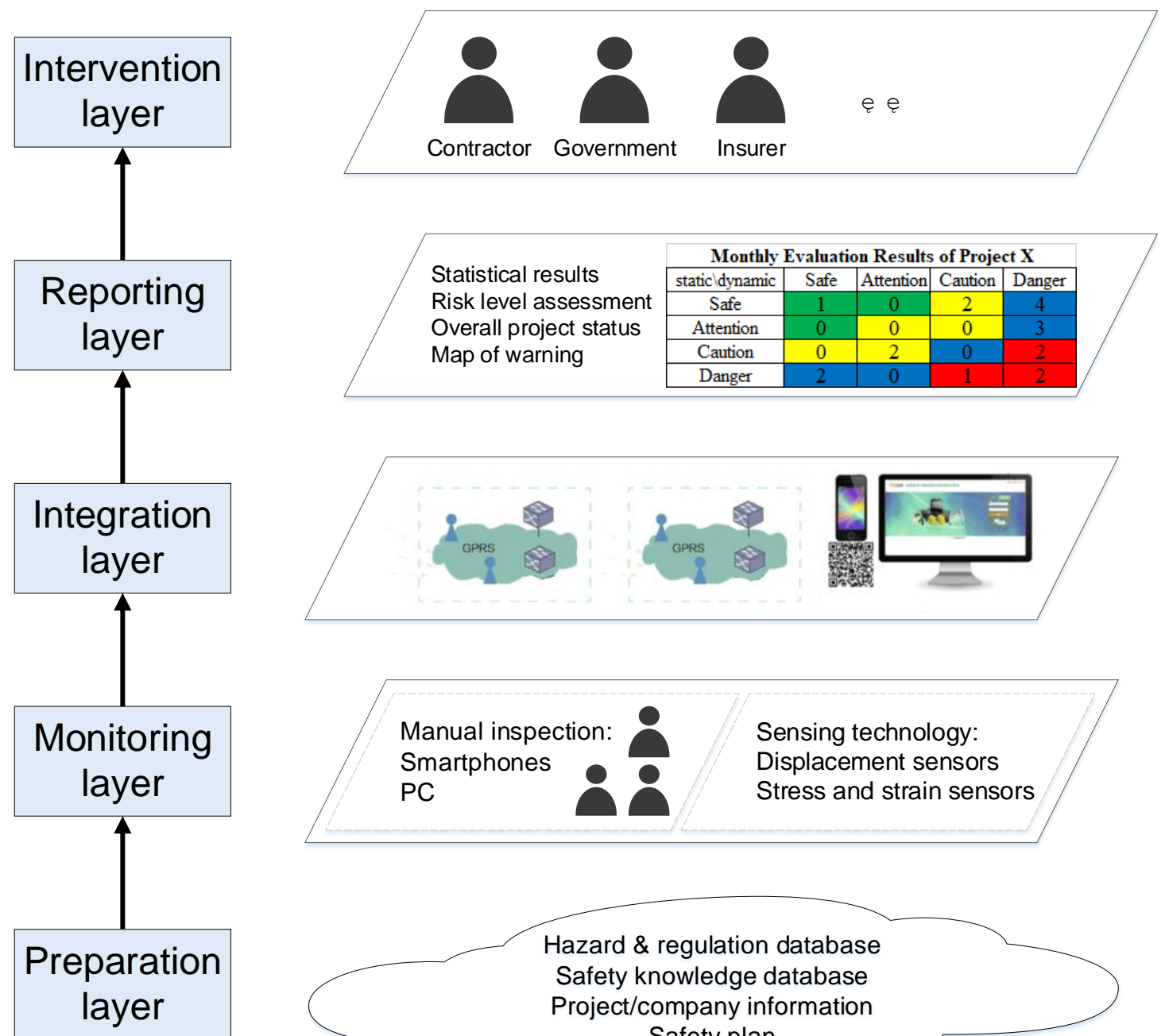

Map of warning

Danger

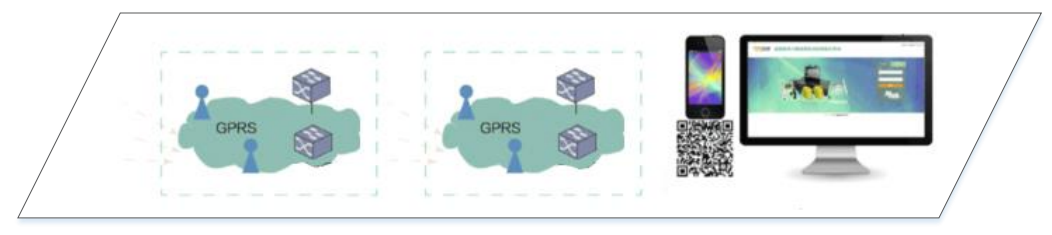

Manual inspection: Smartphones PC

Sensing technology:

Displacement sensors

Stress and strain sensors

Hazard \& regulation database

Safety knowledge database

Project/company information

Safety plan

Fig. 1. Structure of the proposed collaborative safety management framework

\subsection{Preparation layer}

The preparation layer serves as the database of the framework, containing basic project information, safety plans for each monitored project, regulation documents, and a standard hazard database. The basic information and safety plans for the projects provide necessary background knowledge for the reporting and intervention processes, and the standard hazard database is built to act as the foundation of the safety inspection system. Derived mainly from the JGJ59-2011 Standard for Construction Safety Inspection [45], the database lists 756 hazards classified into different categories to assist the manual inspection process. Additionally, safety laws and regulations at all levels are accessible to all system users, providing an easier approach for obtaining sufficient safety knowledge during the inspection and training periods. 


\subsection{Monitoring layer}

The monitoring layer collects the risk information onsite by two different methods: manual inspection assistance and automatic information collection based on intelligent sensing technology. The first approach for improvement of information collection efficiency consists of the service provider recruiting a team of safety practitioners to join the traditional multiple stakeholder inspection system to conduct site safety inspections. All inspectors from different parties can then adopt a unified inspection system to optimize information integration and collaborative management. With the basic project information and standard hazard database built into the preparation layer, the framework configures a standardized information input template with a hazardspecific checklist for the inspectors. The inspectors can record the hazard items and upload site pictures via smartphone or computer. The second approach for improvement of information collection efficiency is mainly applied to large equipment and temporary facilities (such as tower cranes, foundation pits, etc.) that have measurable status indicators. Through various sensors to measure workload, strain, and displacement, the framework can provide real-time monitoring of the working status of these pieces of large equipment and the structural stability of temporary facilities.

\subsection{Integration layer}

The integration layer is an important link connecting the information input in the monitoring layer with the information output in the reporting layer. The information integration function mainly relies on a website platform and smartphone application program developed in Java. In particular, the safety monitoring platform integrates both intensive manual inspection and smart sensing technologies. While the platform guides safety inspection through human behavior, object condition, and human-object interaction, the operating conditions and environmental factors of large equipment and temporary facilities are monitored and shared in real time through smart sensing technology, as shown in Fig. 2. Based on internet technologies, all collected information in the monitoring layer can be transmitted and displayed on the different terminals of various stakeholders. 


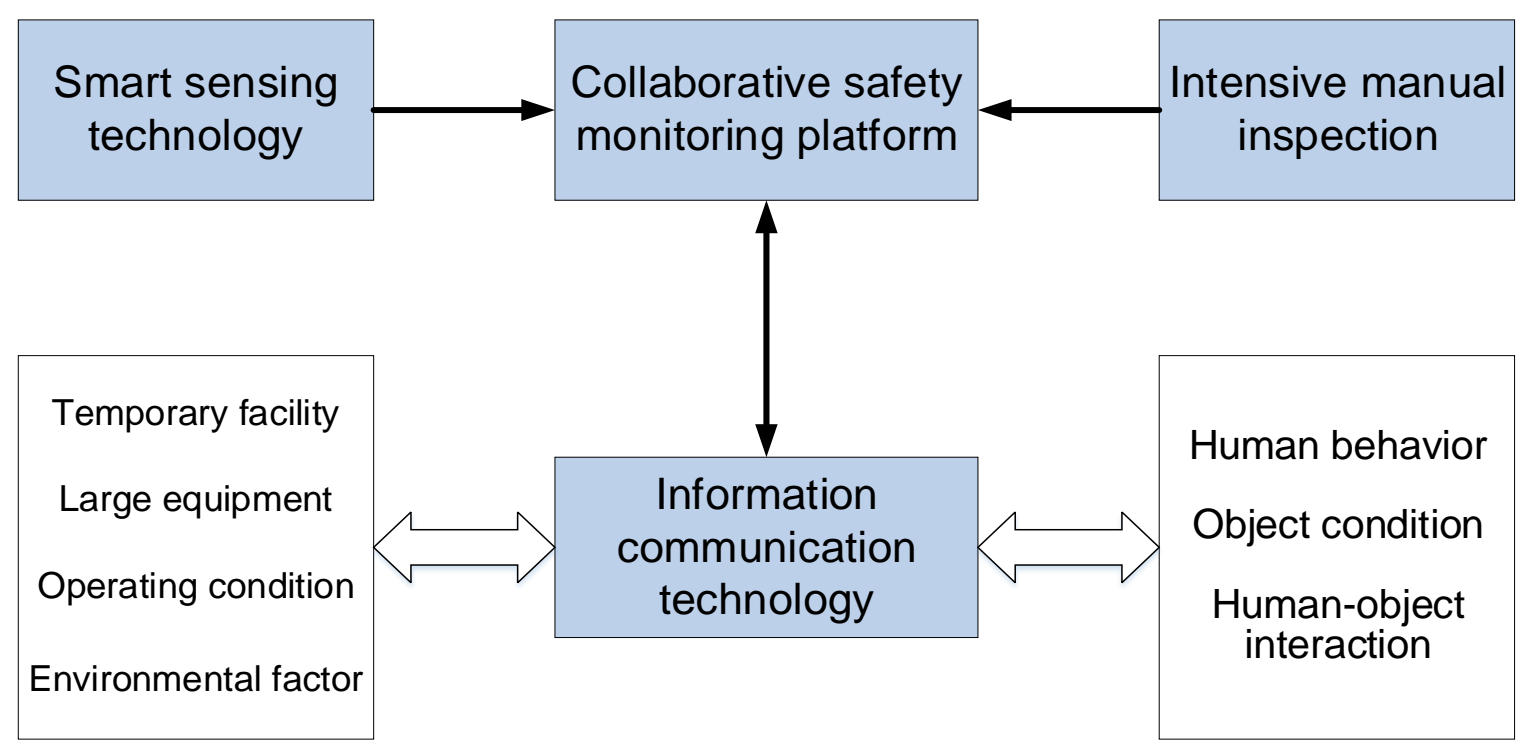

Fig. 2. The integration function of the proposed framework

\subsection{Reporting layer}

The fourth layer is the reporting layer, which summarizes and analyzes all collected information to generate a comprehensive safety assessment for the construction project. This layer is the core application layer and consists of various computer processing algorithms. The safety reports produced by this layer include not only statistical results from the collected information, but also risk ratings for the project. The reports generated by the reporting layer can be classified as two types according to the different requirements of the different stakeholders: area-specific reports and project-specific reports. Applying the data collected in the monitoring layer to the standard assessment indicator system of the preparation layer, hazards detected by initial manual inspection and various smart sensors are assigned different scores. The score of each hazard is calculated as:

$$
\text { score }=\text { frequency } \times \text { severity, }
$$

where frequency is the occurrence count of the hazard over the reporting period and severity represents the severity of the consequences of that hazard, as determined according to the weights given by JGJ59-2011 Standard for Construction Safety Inspection [53]. The static risk level of the project is the sum of all the hazard scores. Additionally, the rectification status, collected from follow-up inspections, is analyzed to generate a dynamic risk level that predicts the future trend of site safety status. Whether the hazard was corrected and whether it was corrected by the deadline are the two major indicators in calculating this warning level. A poor dynamic risk level 
indicates that the project safety is falling short as a result of untimely rectification or negative management attitude, which can result in a high risk level in the foreseeable future. In general, an overall risk assessment value and risk level for the project can be calculated after combining the static risk level and dynamic risk level, offering guidance for administrative intervention.

\subsection{Intervention layer}

The intervention layer indicates the collaborative management framework among all participants. The monitoring records and safety assessment score obtained in the reporting layer provide the government, service provider, and general contractors with a full and comprehensible understanding of their projects, and helps them to identify critical issues of safety management and prevent risks by implementing timely countermeasures. Safety practitioners who are tasked by the service provider with conducting site inspection can also give professional advice to the general contractors on safety management according to the monitoring reports.

Overall, all stakeholders are integrated in a collaborative platform and they can view the detailed records of daily safety inspections and real-time work statement of mechanical equipment. Authorized party such as the government can send rectification reminders to the responsible parties through the system and check the rectification situation at any time. The government can formulate an evidence-based safety policy, and the service provider can also adjust insurance premium accordingly as per the collected information.

\section{Prototype system and case study}

To validate the feasibility and practicality of the proposed framework, a prototype was developed with the help and technical support from a local insurance company. The prototype was then tested in a case study for seven ongoing construction projects in Qingdao with the support of the local government. To protect certain commercially sensitive information, Fig. 3 illustrates an overview of the system architecture of the prototype. 


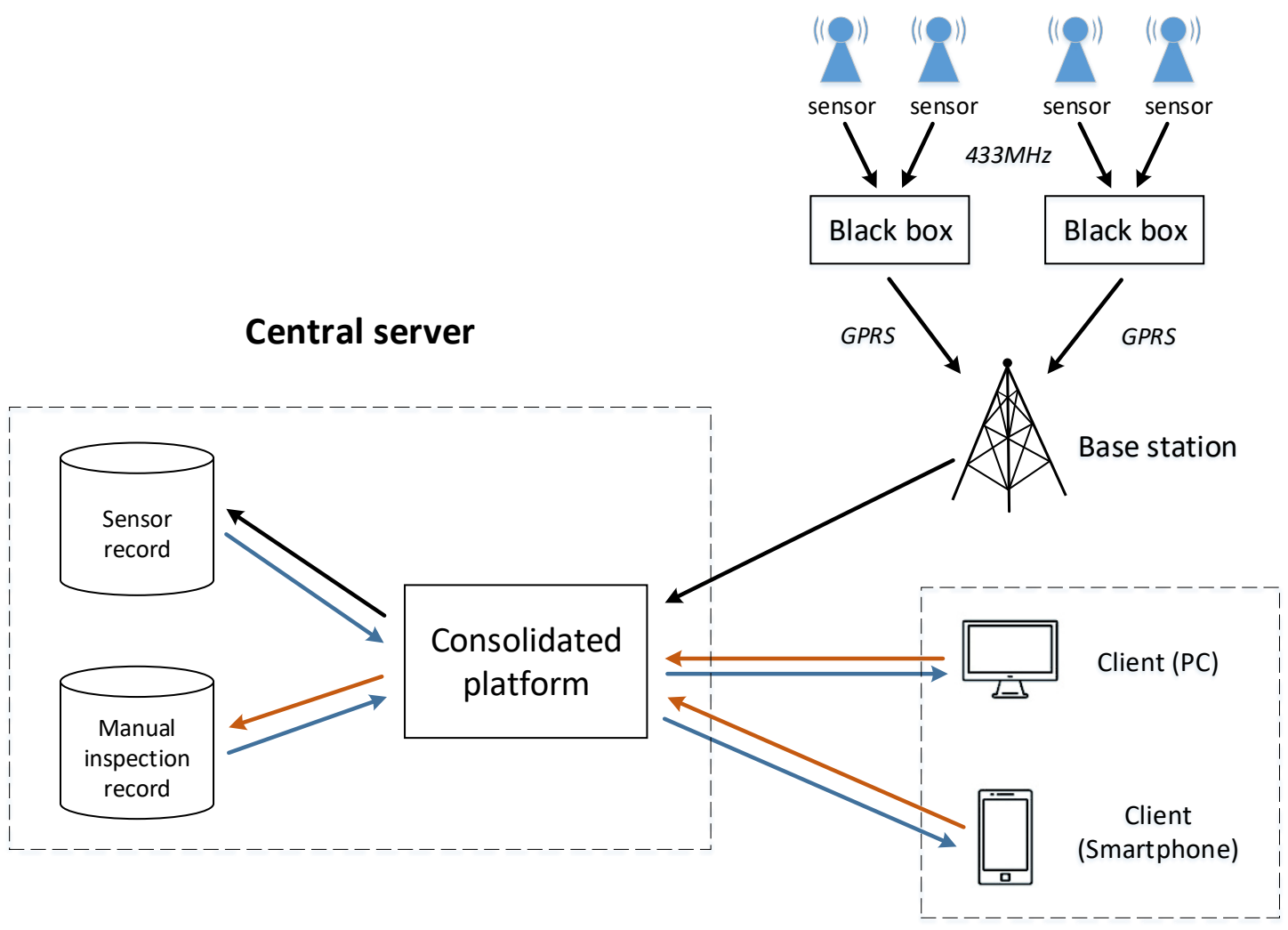

Monitoring terminal

Fig. 3. Prototype architecture

First, various sensors are installed to measure the environmental conditions and operating conditions of the large equipment and temporary facilities, including weight, angle, air velocity, amplitude, and height. The information is transferred to the host of the sensor system (a black box) via a $433 \mathrm{MHz}$ network. The information is collected by the base station each minute via the GPRS network, which is stored in the central server for dissemination.

The central server also stores and disseminates the manual inspection record. This central server is built using the Alibaba Cloud computing system for virtual hosting, storage, and data communication. The information from the central sever and the sensor record are synchronized and function in a consolidated platform. The consolidated platform can also be treated as a computing interface, which is developed using Eclipse and supported by its own MySQL database. Analytical algorithms have been written and are operated using Java behind the Eclipse and MySQL.

Apart from viewing the information from interface of the consolidated platform, users can also insert the manual safety inspection data through a PC website or 
smartphone application, which are both developed on Java with Eclipse. And all collected information in the monitoring layer can be processed and transmitted to different terminals and stakeholders.

As this prototype was developed during a preliminary stage of the research, only three key stakeholders were included in the testing: service providers (i.e., insurance company), local government, and general contractors. Other stakeholders, such as the owners, supervising engineers, or subcontractors, are not specifically addressed in this prototype because: (a) they share certain similarities in the information asymmetry relationship, (b) they hold relatively minor positions in the management system, and (c) time and resource constraints at this preliminary stage of prototype testing prohibited a more comprehensive test.

In accordance with the proposed framework, the prototype was designed with four modules: summary dashboard, site inspection module, real-time monitoring module, and safety training module. The safety information input interface is located in both the site inspection and real-time monitoring modules. After carefully assessing and sorting the information in these modules, different stakeholders can access the information according to their project requirements and management strategies.

\subsection{Information input}

One of the key features of this prototype is its simple data input for manual safety inspection records. Figure 4 shows the main view of the recording interface. The platform identifies the person currently logged in (e.g., safety expert from the service provider, government officer, or project safety inspector). The inspector can only create new inspection records in the appropriate directory for the user. When inserting a new safety record, the inspector is first presented with a template (Fig. 4(a)) that requires basic information. Once this basic information is entered, the inspector can add detailed inspection content by clicking on the green "plus" sign, causing the recording view shown in Fig. 4(b) to appear. The built-in standard hazard database helps guide the inspector through the hazard selection process. The inspector can either choose an exact hazard description or skip the category selection step to type in keywords to find the specific hazard description that best describes the site situation. A new hazard can also be added and the system will automatically read the severity rating and suggested corrective actions of the selected hazard from the built-in standard hazard database. Site 
418 pictures of the corresponding hazard can be uploaded, and the inspector assigns a 419 rectification deadline for the hazard. When all the detected hazards are collected, the 420 inspector can generate comprehensive suggestions and inspection plans for the item. 421 Then, a record code will be automatically generated and saved for future reference.

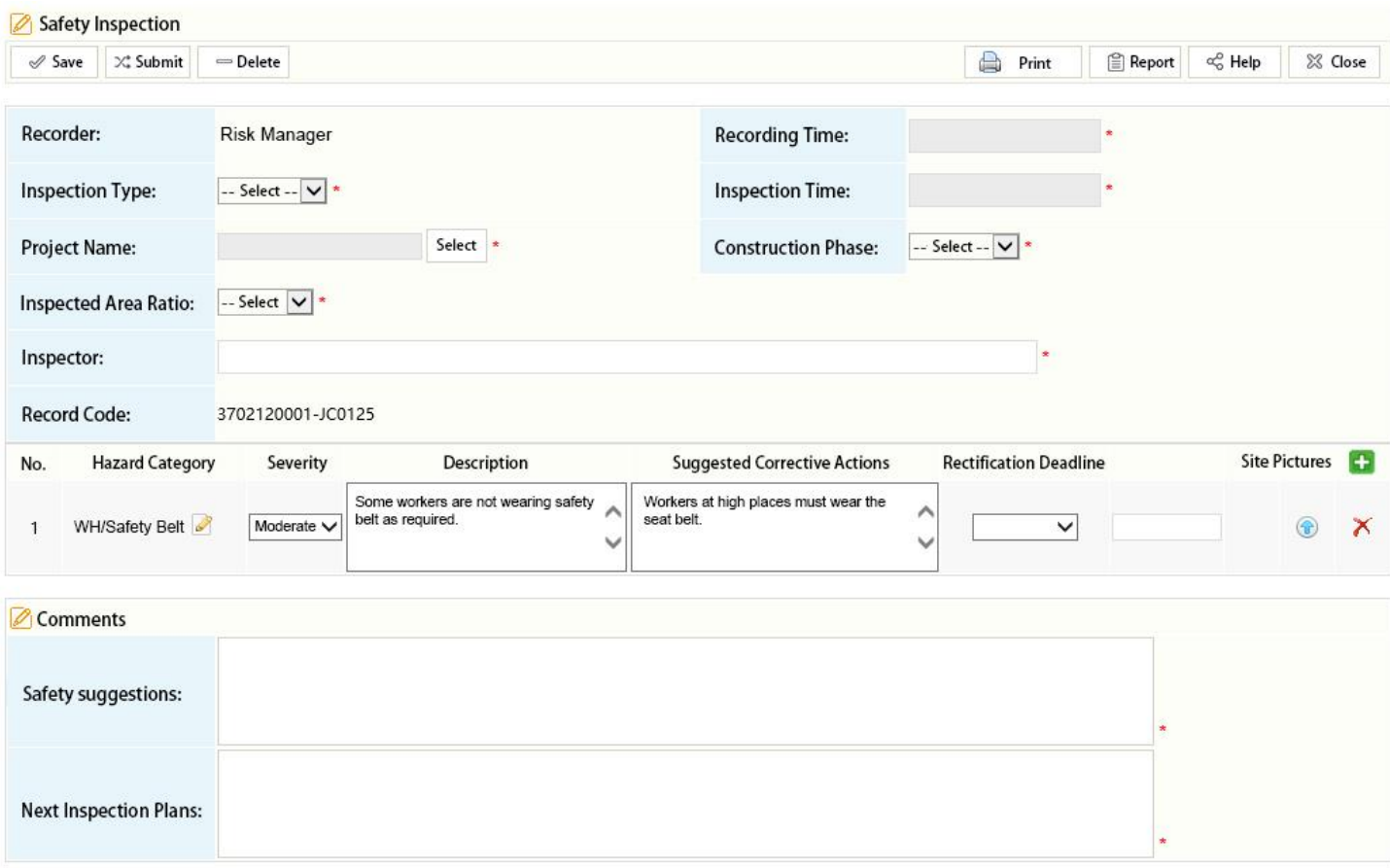

(a) Basic information input

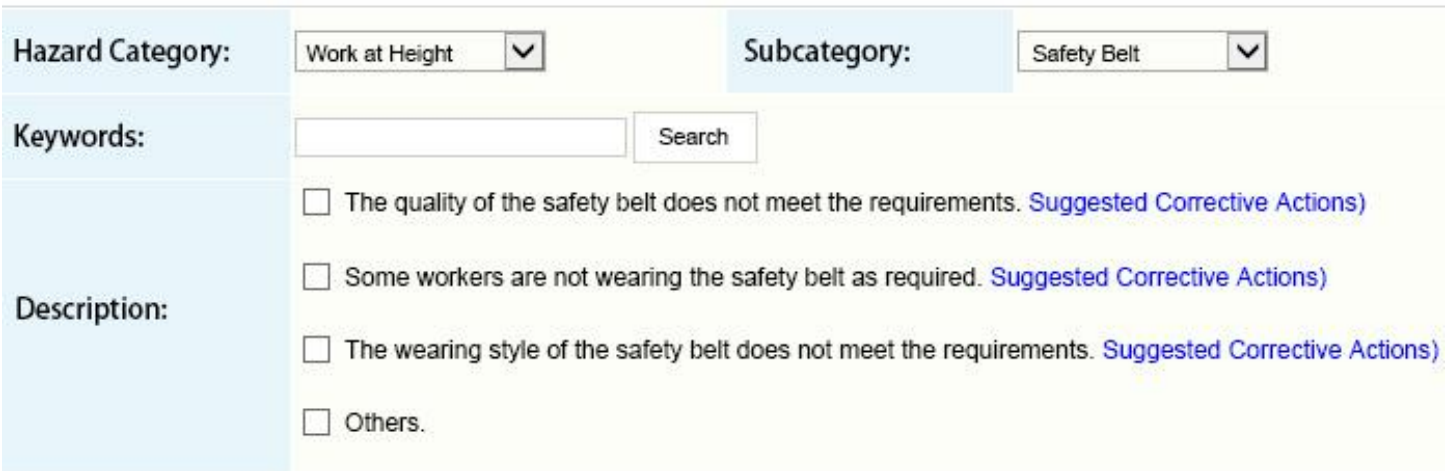

The proposed platform also has an integrated real-time monitoring module for large equipment and temporary facilities. This module takes advantage of quantifiable data related to the monitored object and the real-time monitoring function also compensates 
for drawbacks of human inspection, such as inefficiency and inaccuracy, when inspecting large equipment and facilities. As one of the largest pieces of equipment on most construction sites, tower cranes were selected for testing in this case study. Five sensors were installed on each tower crane to collect real-time weight, angle, air velocity, amplitude, and height data. These data were analyzed and transmitted through a GPRS network to the platform system every minute (Fig. 5). The purpose of this module is to capture the operating conditions and environmental information of the tower crane to prevent overloading, collision, and overturning risks in real-time.

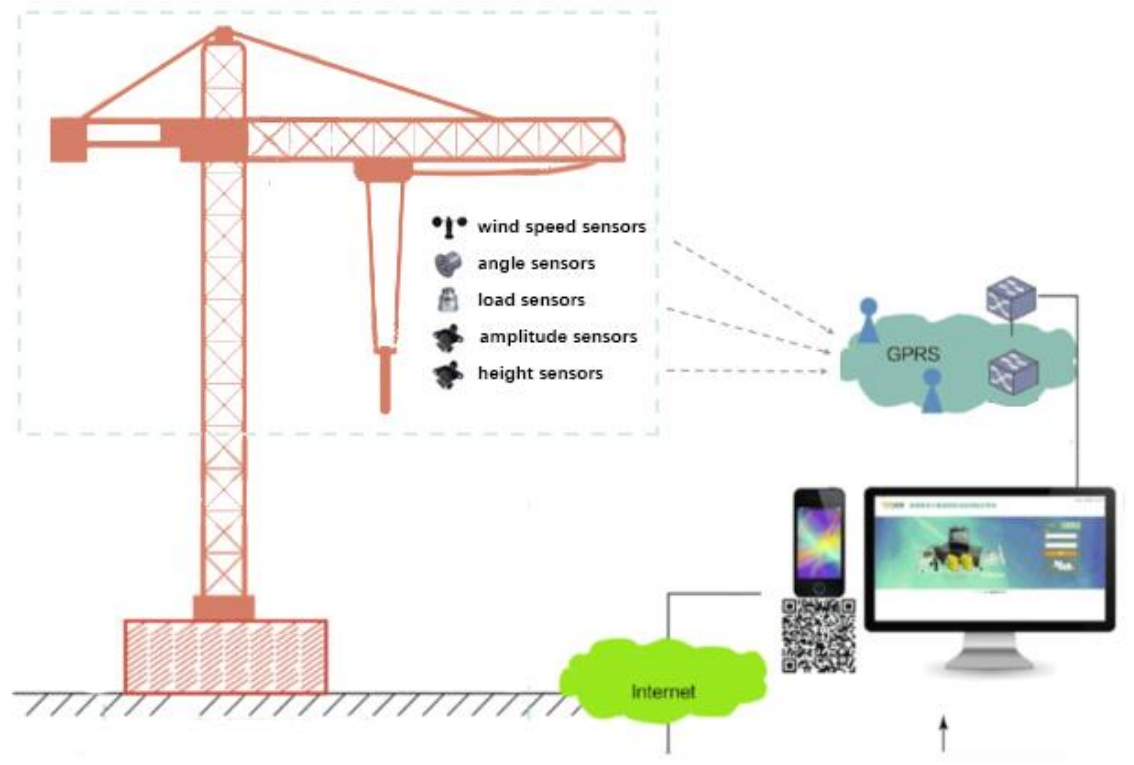

Fig. 5. Real-time monitoring for large equipment

\subsection{Safety report}

The information collected through the safety inspection and various sensors can be analyzed to generate a safety assessment of each construction project. This safety report not only displays the original input data and its statistical results, but also includes the overall risk ratings for each project. The detailed calculation methods for these ratings are explained in Section 3.4. In general, the safety reports take two forms corresponding to two types of information: project-specific reports and area-specific reports, provided according to the different management characteristics and requirements of each stakeholder. Table 2 illustrates the different authority limits of the government, service provider, and the contractors with regard to the various reporting functionalities of the proposed real-time safety management platform. General contractors can only obtain a safety report for their own project in order to conduct targeted improvements in safety. Because the local government and service provider are taking the lead in external audits 
457 and management intervention for all construction projects, they require a risk warning 458 report on a more macroscopic level, as well as to evaluate the management system and 459 to help determine management priorities and evaluate their own performance. At the 460 same time, they also require detailed risk reports for each project to provide safety 461 advice or supervise rectification actions. In the long run, this two-level approach 462 ultimately helps to establish a safety credit and qualification system for all construction 463 companies, providing a foundation for a future bidding and insurance rate setting 464 procedures. 


\begin{tabular}{|c|c|c|c|c|}
\hline & & \\
\hline & & $\begin{array}{c}\text { Local } \\
\text { government }\end{array}$ & $\begin{array}{l}\text { Service } \\
\text { provider } \\
\text { (Insurance } \\
\text { company) }\end{array}$ & General contractor \\
\hline \multirow{4}{*}{ Summary dashboard } & Project/company information & $\mathbf{A} / \mathbf{P}$ & $\mathbf{A} / \mathbf{P}$ & $\mathbf{P}$ \\
\hline & Codes/standards & $\mathbf{A} / \mathbf{P}$ & $\mathbf{A} / \mathbf{P}$ & $\mathbf{A} / \mathbf{P}$ \\
\hline & Warning map & $\mathbf{A} / \mathbf{P}$ & $\mathbf{A} / \mathbf{P}$ & $x$ \\
\hline & Hazard distribution & $\mathbf{A} / \mathbf{P}$ & $\mathbf{A} / \mathbf{P}$ & $\mathbf{P}$ \\
\hline \multirow{3}{*}{$\begin{array}{c}\text { Safety management } \\
\text { module }\end{array}$} & Safety plan & $\mathbf{A} / \mathbf{P}$ & $x$ & $\mathbf{P}$ \\
\hline & Individual inspection record & $\mathbf{A} / \mathbf{P}$ & $\mathbf{A} / \mathbf{P}$ & $\mathbf{P}$ \\
\hline & Hazard rectification status & $\mathbf{A} / \mathbf{P}$ & $\mathbf{A} / \mathbf{P}$ & $\mathbf{P}$ \\
\hline \multirow{3}{*}{$\begin{array}{l}\text { Real-time monitoring } \\
\text { for equipment / temp. } \\
\text { facility module }\end{array}$} & Site-specific warning & $\mathbf{A} / \mathbf{P}$ & $\mathbf{A} / \mathbf{P}$ & $\mathbf{P}$ \\
\hline & Equipment-facility specific warning & $\mathbf{A} / \mathbf{P}$ & $\mathbf{A} / \mathbf{P}$ & $\mathbf{P}$ \\
\hline & Historical data & $\mathbf{A} / \mathbf{P}$ & $\mathbf{A} / \mathbf{P}$ & $\mathbf{P}$ \\
\hline \multirow{2}{*}{ Safety training module } & Demographic information & $\mathbf{A} / \mathbf{P}$ & $x$ & $\mathbf{P}$ \\
\hline & Statistical results & $\mathbf{A} / \mathbf{P}$ & $\mathbf{A} / \mathbf{P}$ & $\mathbf{P}$ \\
\hline
\end{tabular}

Note: "A/P" denotes access to both area-specific and project-specific assessment, " $P$ " denotes access to project-specific assessment, and “ $\times$ ” denotes no access. 


\subsubsection{Project-specific assessment}

Figure 6 shows the safety inspection module depicting every hazard documented in the manual safety inspections (Fig. 6(a)) and the corresponding rectification status of the hazards (Fig. 6(b)) for a specific project. This constitutes the primary outcome of the manual inspections. The inspection records for the specific project shown in Fig. 6(a) are the same as those initially input by the professional safety inspector. The rectification status view shown in Fig. 6(b) provides the rectification deadline for each hazard and a regularly updated rectification status. General contractors are able to obtain constantly updated safety inspection records for their own project so they can rectify detected hazards in a timely manner. After the hazard has been rectified, they can update the status of the hazard with pictures of the same location. Service providers can obtain feedback from the safety expert team and designate inspectors to confirm the rectification process according to the uploaded pictures, improving project safety. The local government can use this information to gain a detailed understanding of project risk information, allowing it to send more timely orders for rectification and supervision, and provide intangible behavioral constraints on the general contractors, encouraging them to improve their safety performance.

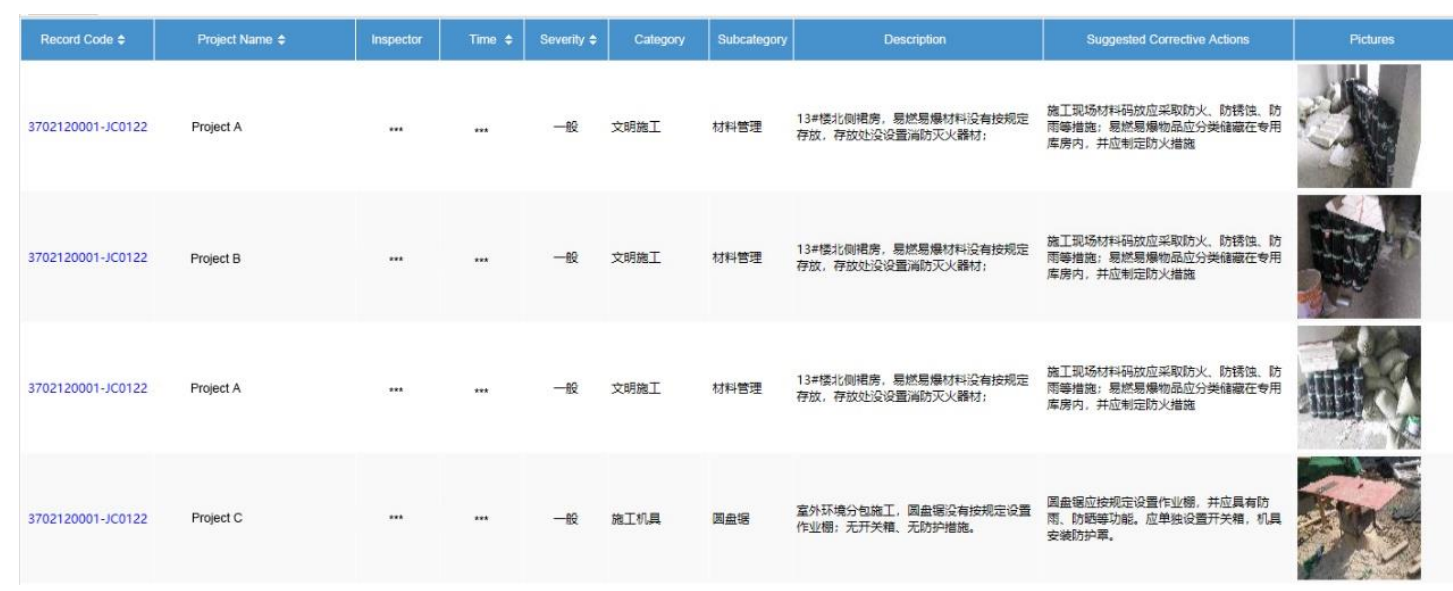

(a) Manual inspection record

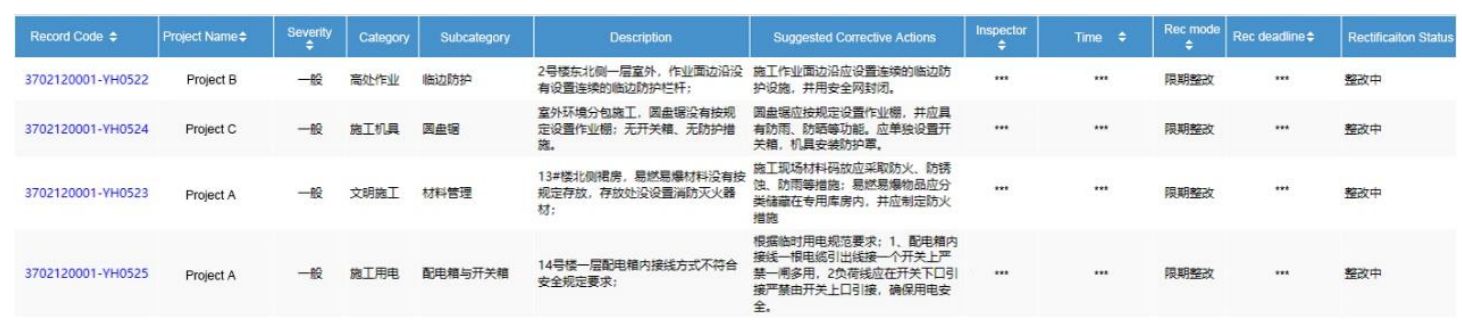

(b) Rectification status

Fig. 6. Safety inspection module 
Given a specific time period, the platform can also generate a report on the distribution of hazard types and trends of risk levels for a specific project, as shown in Fig. 7. Hazard distribution statistics directly describe the hazard records of the project and generalize the occurrence of different types of hazards over a specific period. The trend chart of the risk level reflects the change in overall risk status considering the occurrence and rectification of hazards. These statistical results not only help managers to summarize the pattern of hazard occurrence and assist general contractors in identifying key points for safety management, but also provide a practical basis for improving the supervision and inspection plans of the service provider and local government. For example, Fig. 7 shows all the hazard statistics and the risk level trend information from the start of a monitored project. It can be concluded that falls and electrical hazards have the highest frequency of occurrence. And the risk level trend graph exhibits two significant peaks, corresponding to the start-up and the fit-out of the project. This suggests that managers need to pay more attention to large equipment installation and subcontractor selection during the fit-out process, and strengthen the supervision and control of work at great heights and with electricity.
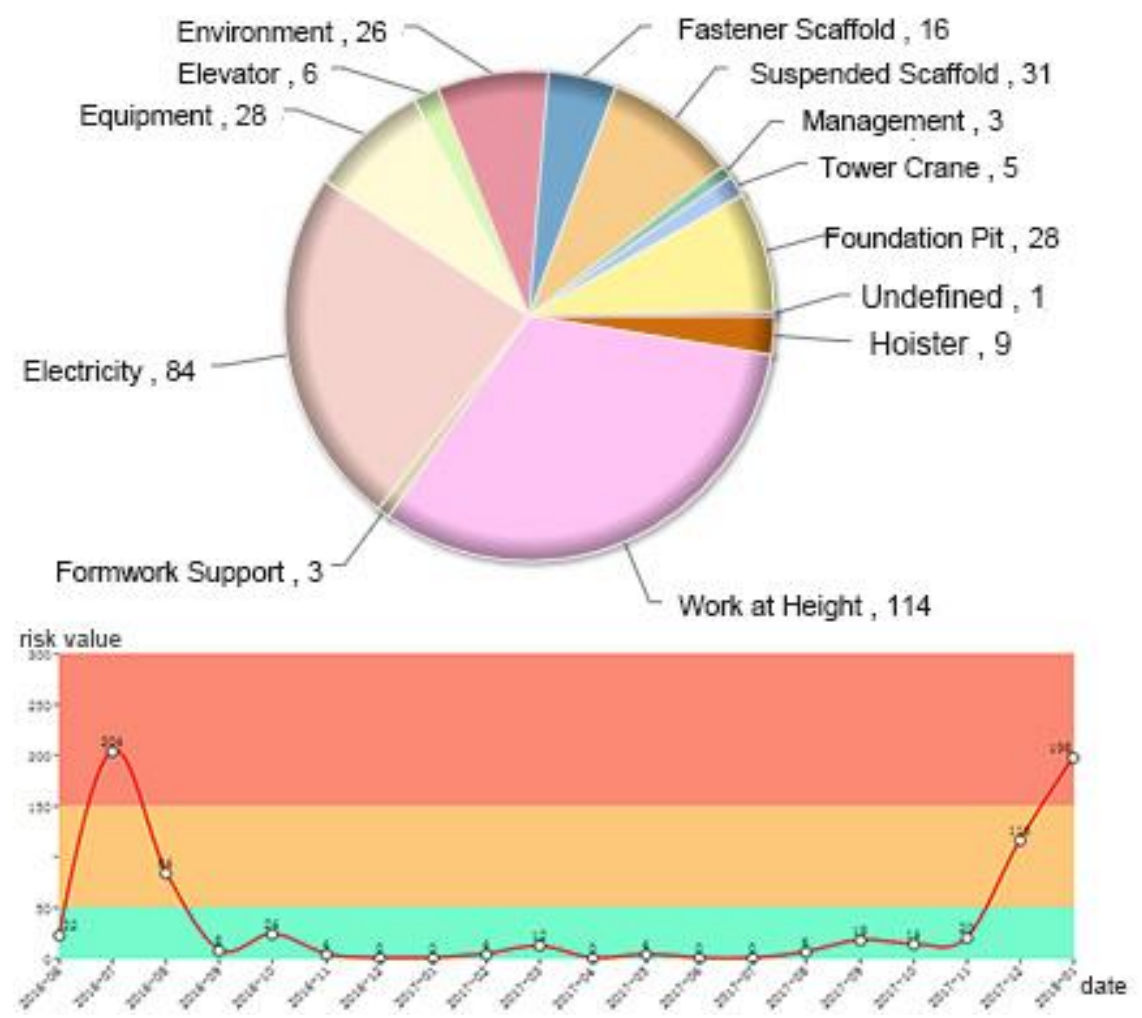

Fig. 7. General management module: hazard analysis

Rather than being constructed of discrete reports like the safety inspection module, 
the real-time monitoring module receives near-continuous data from various sensors, enabling the display of the real-time working conditions of large equipment (such as tower cranes). As shown in Fig. 8(a), working status is divided into five levels in order of increasing severity: offline, normal, reminding, warning, and violating. To make the output of the monitoring more intuitive, the simulated model transforms the sensormeasured data and relative positions of the cranes into images (Fig. 8(b)). Using these data, the system further calculates the moment in the tower crane and monitors the environmental risks associated with wind speeds and the risks of overloading, overturning, and collision during operation. The real-time monitoring module greatly improves the risk warning capability of the collected risk information. When an abnormal event occurs, the system automatically sends prompt messages to the operating driver and project managers to help prevent accidents in a timely manner. Additionally, the intuitive real-time data display and summarized high-frequency data compensate for the blind spots in the manual data collection method, strengthening supervision.

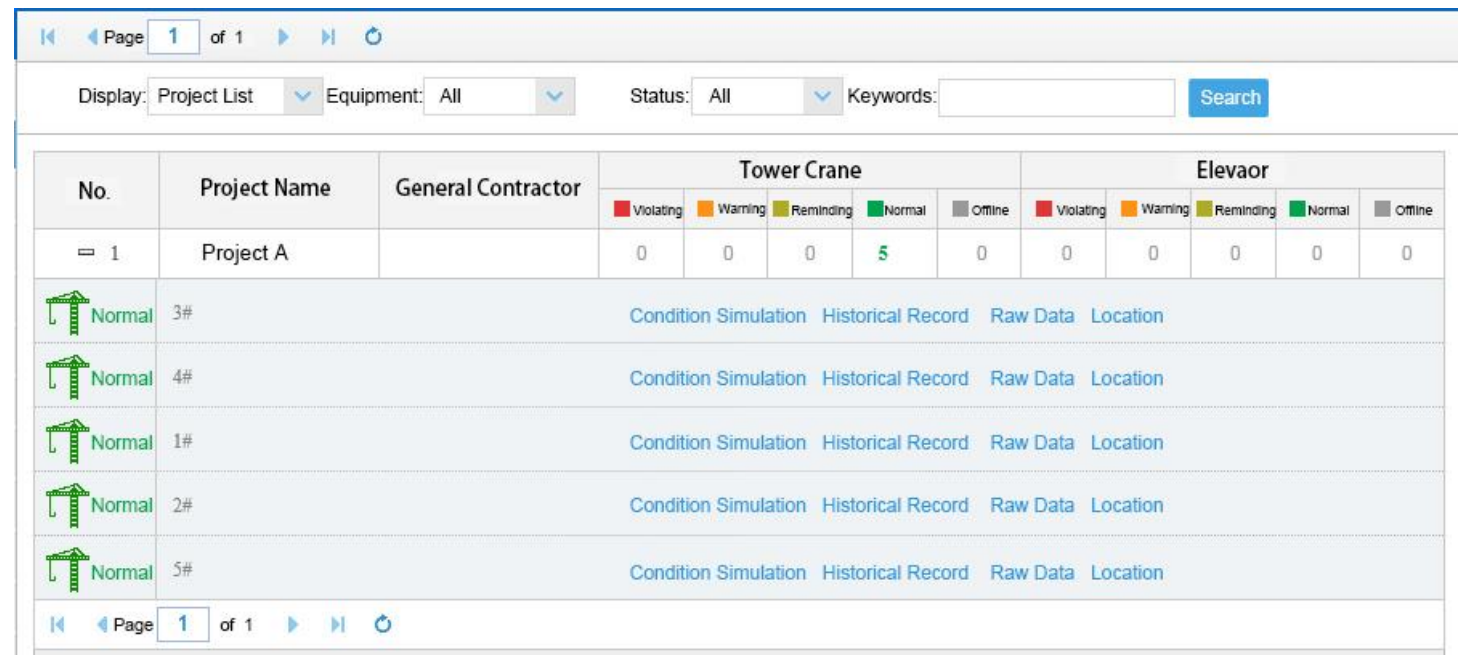

(a) Real-time status 


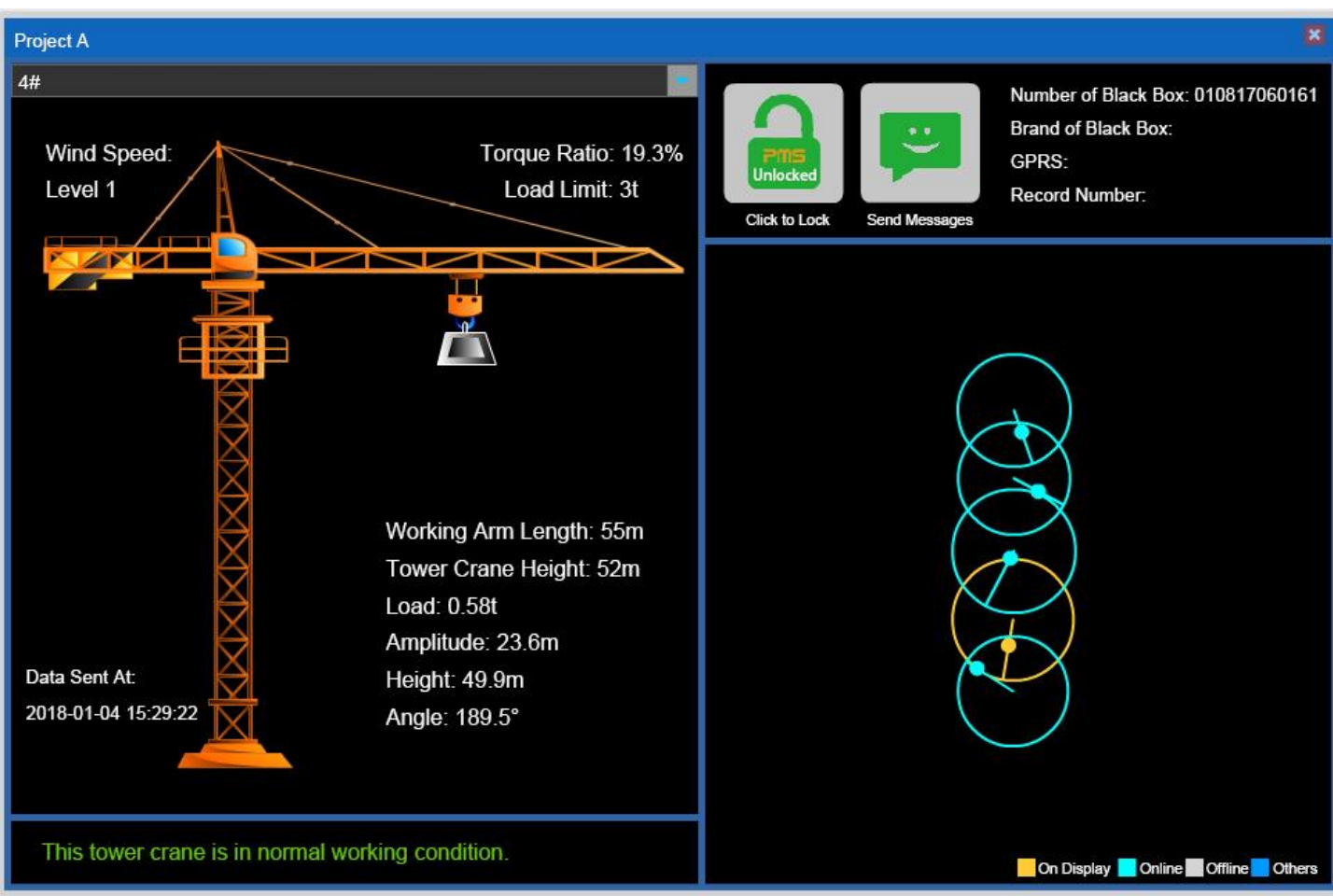

(b) Simulated model

Fig. 8. Real-time monitoring module

With a strong capacity for information integration, the proposed platform also incorporates existing safety training workshops to provide a more effective safety management process throughout the project. Safety practitioners from the service provider can use a toolbox to help workers. To ensure the reliability of training records, workers log into the system with their ID cards before receiving training and completing an examination. Training and examination records are then automatically uploaded to the system. The summary box at the top of Fig. 9 shows the training information generated by the toolbox system. The histogram shows the number of people who received the safety training (in yellow) and the number of people who passed the exams (in green). The line graph depicts the monthly training trend. Stakeholders are warned when the pass rate becomes low or a continuous training approach is required. Construction project managers can use this information to identify construction teams with weak safety knowledge and improve project safety culture through retraining and other management measures. 


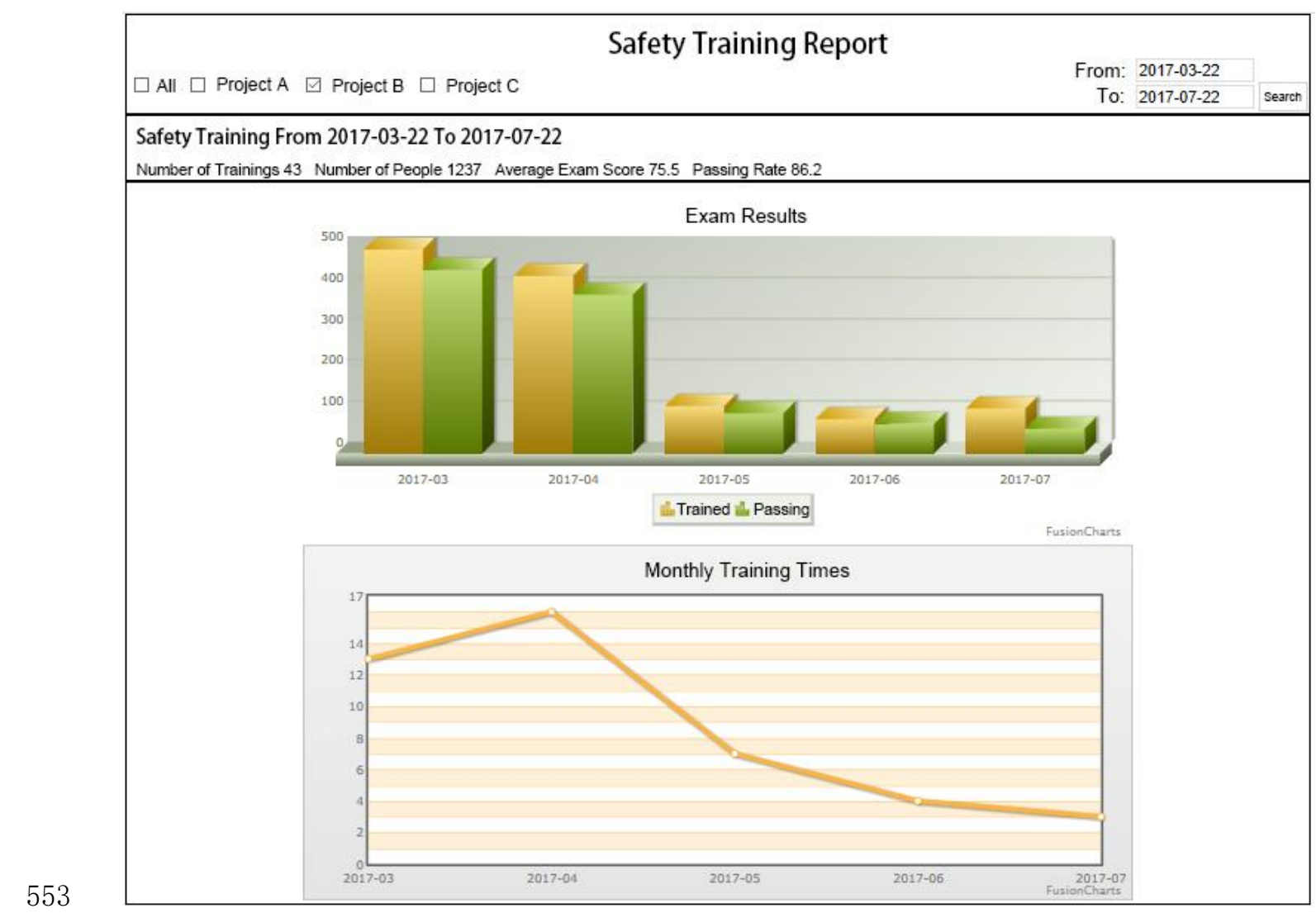

Fig. 9. Safety training module: statistical results

\subsubsection{Area-specific assessment}

The warning map view (area-specific) in the general management module is designed to provide the government and the service provider with a comprehensive understanding of the warning levels of all ongoing projects in a specific district. The warning levels are calculated based on rectification status and are divided into four grades: low risk, attention, caution, and danger, indicated by blue, yellow, orange, and red points, respectively. In the warning map in Fig. 10, two projects are rated at the caution level, and five are rated as low risk for good rectification performance. 


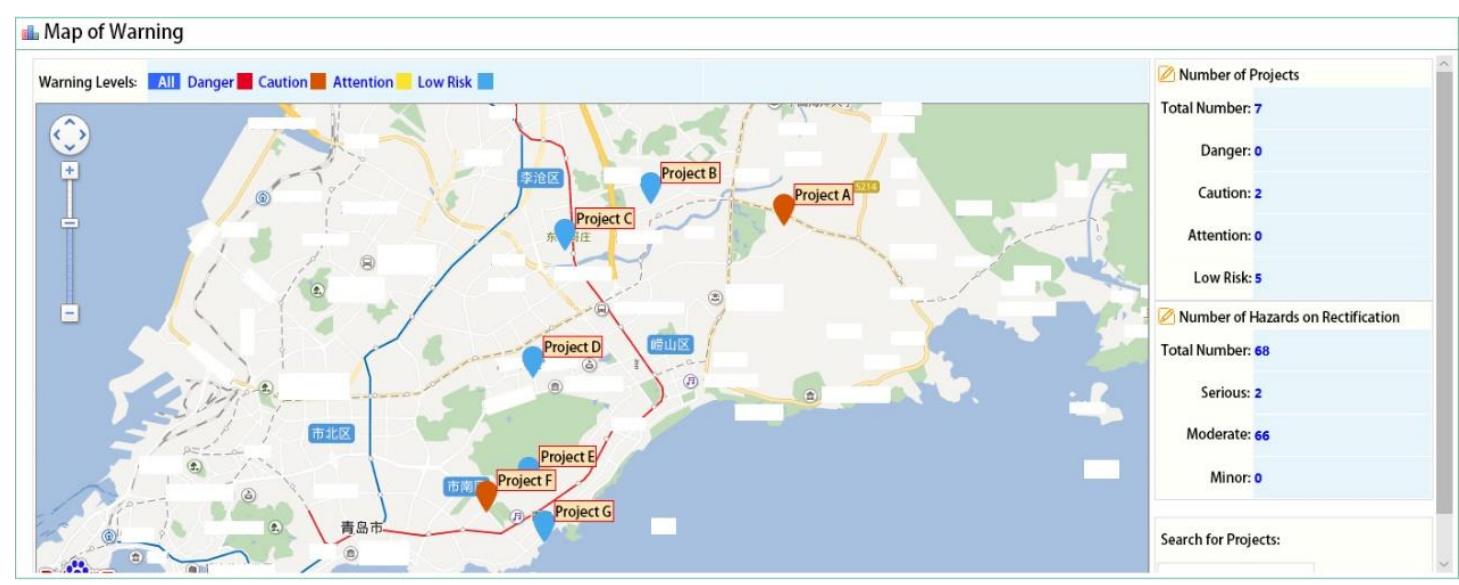

Fig. 10. General management module: warning map

Users can select a specific period of time for a summary of large equipment statuses in the real-time monitoring module. Figure 11 indicates that there are four sets of equipment being monitored each day over the defined period, and that the online ratio is $100 \%$. The module also lists projects on the left side of the view according to when their equipment has been detected to be abnormal too many times within the given period, which is useful for management purposes. Similar to the warning map, this view also identifies the riskiest projects, helping the government and the service provider to identify the prime target for intervention.

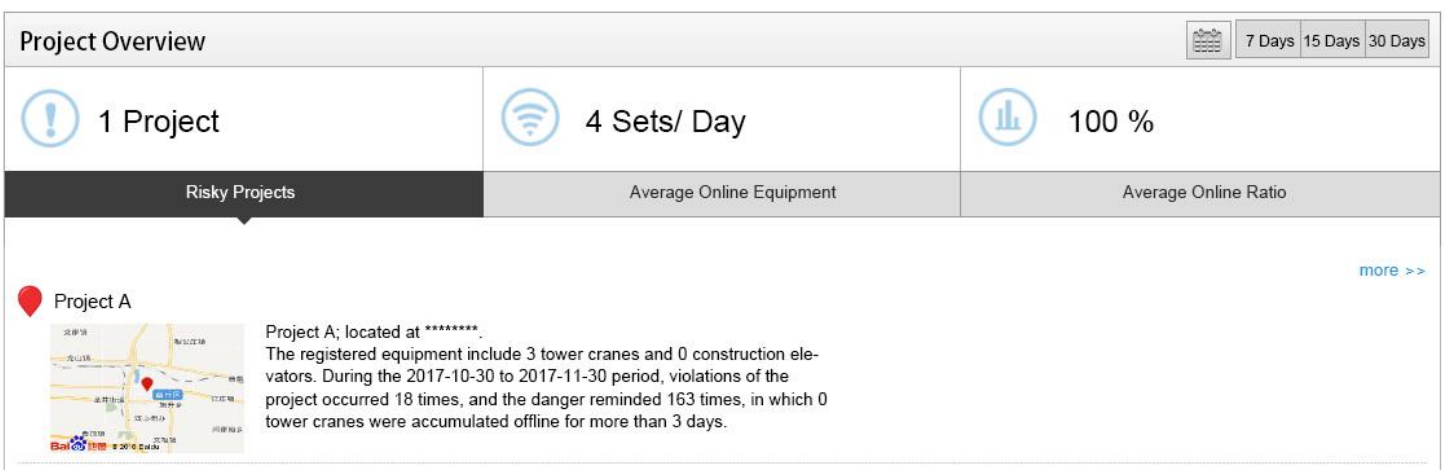

Fig. 11. Real-time monitoring module: project overview

The macro-regional area safety assessment report can help the local government and service provider understand the overall risk status of all projects in a region and identify the projects with poor safety performance. Using project-specific safety reports, they can also determine the targets and objectives of their intervention actions, such as training, consulting services, penalties, or incentives. Once the proposed framework has been widely adopted, the area-specific assessment could also be utilized from within 
governmental and service provider organizations to provide a foundation for evaluating the management performance of the government and safety expert teams in a specific district.

\section{Discussion}

\subsection{Practical implications}

The application of the proposed framework and platform has received strong support from the local government in Qingdao, China. The government paid for the service provider (insurance company) and chose seven ongoing projects that would be required to use the proposed system. Under the same set of inspection metrics, some of the pilot projects were found to be in a poor state regarding safety management in the early stage, but with the ongoing application of the proposed platform, the safety management status significantly improved in the short term. No fatal accidents occurred during the construction of any of the pilot projects. User feedback indicated that the proposed system was welcomed by the involved stakeholders. First, the proposed prototype indirectly increased the inspection frequency from the local government perspective due to the accessibility of real-time safety information, addressing the limitation of the shortage in professional safety inspectors, and strengthening the information disclosure mechanism of projects in the jurisdiction. Second, a change in the attitude of general contractors was observed. In the beginning, contractors expressed resistance to such close monitoring by government departments. However, as the trials matured, they realized that their efforts in the rectification of hazards were being recognized and appreciated. This encouraged contractors to be more open to information disclosure. Wider adoption of the proposed framework can help to improve the safety status of a project while making it easier for the government to obtain sufficient reliable safety information.

Furthermore, users from different parties were invited to give their feedback and evaluation by rating their satisfaction on four questions after using the platform in Qingdao. The rating for each question ranged from 0 (extremely dissatisfied) to $100 \%$ (extremely satisfied). The questionnaire was sent online to 62 safety practitioners who used the prototype using the contact information provided by the local government in Qingdao, China. A total of 49 respondents provided their feedback, with 9 of them from the local government, 22 from the general contractor, and 18 from the service provider. 


\begin{tabular}{clcc}
\hline No. & \multicolumn{1}{c}{ Evaluation variables } & Mean (\%) & Interpretation \\
\hline 1 & Convenience of information input and output & 87.98 & Satisfied \\
2 & Clarity and sufficiency of information & 87.49 & Satisfied \\
3 & $\begin{array}{l}\text { Efficiency and accuracy improvement for safety } \\
\text { inspection tasks }\end{array}$ & 88.80 & Satisfied \\
4 & $\begin{array}{l}\text { Effect on improving the safety status of } \\
\text { construction projects }\end{array}$ & 86.55 & Satisfied \\
\hline
\end{tabular}

Most of the respondents had 10 or more years of work experience. Table 3 shows the results of evaluation for the proposed platform.

On average, all the variables were rated above the satisfaction level of $70 \%$. Thus, it indicates that the proposed platform is user-friendly regarding the information input and output functionality, and information provided by the platform is clear and sufficient for project safety management. As for the implementation effect, it shows a positive outcome for improving safety inspection tasks and project safety status. In addition, some respondents also suggested that the platform should add more functionalities, like adaption to local standards and live site broadcasts.

Table 3. Results of platform evaluation 
the contractor tends to hide the facts from external parties, including the government and insurance companies, for fear of damage to corporate reputation and delay of progress. With compulsory social insurance for workplace injuries already in place, most contractors regard commercial construction safety insurance as an unnecessary cost, rather than an effective method of risk transfer. Until the industrial and safety awareness system is sufficiently developed, it remains necessary to find new modes of cooperation and methods to promote the use of safety frameworks, such as the one proposed in this paper.

\subsection{Theoretical contributions}

The first theoretical contribution of this study lies in the collaborative working environment that includes all stakeholders in promoting and improving safety inspection and monitoring. This collaborative approach has uncovered the connections between the interests of all parties, bridging a research gap present in previous studies that focused more on real-time data collection and recording without functions for realtime assessment and warning. Another theoretical contribution of this study is that the collaborative framework expands the role of engineering insurance in safety management, while simultaneously supporting the maturation of the engineering insurance market. Furthermore, the current research also contributes to improved safety performance by providing a harmonious and constructive platform for safety promotion, as demonstrated in the prototype. This leads to mutual benefits for all parties involved in a project and promotes continuous improvement in safety inspection and monitoring.

\subsection{Application scenarios}

The prototype is currently capable of three important application scenarios, namely, on-site large equipment monitoring, manual or automated inspection combination, and a macroscopic display of safety monitoring across projects. The functionality of large equipment monitoring is developed through smart sensing technology to collect measurable operating factors and give real-time operating condition reports of the equipment or facilities. In large projects with a variety of equipment and temporary facilities, this will be very helpful because it can significantly reduce the manual inspection effort, while improving inspection accuracy and efficiency. The real-time condition of all equipment and facilities are displayed on one screen, enabling efficient safety monitoring and management. The second application scenario is the combination 
682 of manual or automated inspection to achieve multi-source data integration and 683 comprehensive risk analysis. This will be the most practical function to address 684 complex construction practices. Safety practitioners from different stakeholders can 685 share the inspection results on the same platform, and the data from manual inspection 686 and automatic collection can be analyzed in the same evaluation system. The output 687 descriptive results and comprehensive ratings can help identify the focus of future 688 management. Lastly, the prototype is capable of providing a macroscopic view of safety 689 monitoring across projects. The display of the safety status allows governments to 690 effectively implement a wide range of industry regulations. The regulations can be 691 extended to larger areas, even across the entire country. Table 4 shows the three possible 692 application scenarios of the prototype and their affecting layers in the management 693 framework, with corresponding sample figures and remarks.

694

695

Table 4. Application scenarios

696

\begin{tabular}{|c|c|c|c|}
\hline Current scenario & Affected layers & $\begin{array}{c}\text { Analysis and } \\
\text { outcomes }\end{array}$ & Remarks \\
\hline $\begin{array}{l}\text { Large equipment on-site } \\
\text { monitoring }\end{array}$ & $\begin{array}{l}\text { Monitoring layer } \\
\text { Reporting layer }\end{array}$ & $\begin{array}{l}\text { Figure } 5 \\
\text { Figure } 8\end{array}$ & $\begin{array}{l}\text { It can be applied to large projects with a } \\
\text { variety of equipment and temporary facilities }\end{array}$ \\
\hline $\begin{array}{l}\text { Combination of manual or } \\
\text { automated inspection on } \\
\text { jobsite }\end{array}$ & $\begin{array}{l}\text { Monitoring layer } \\
\text { Integration layer } \\
\text { Reporting layer }\end{array}$ & $\begin{array}{l}\text { Figure } 4 \\
\text { Figure } 5 \\
\text { Figure } 6 \\
\text { Figure } 7 \\
\text { Figure } 8\end{array}$ & It can be used for comprehensive risk analysis \\
\hline $\begin{array}{l}\text { Macroscopic view of safety } \\
\text { monitoring across projects }\end{array}$ & $\begin{array}{l}\text { Preparation layer } \\
\text { Reporting layer } \\
\text { Intervention layer }\end{array}$ & $\begin{array}{l}\text { Figure } 10 \\
\text { Figure } 11\end{array}$ & It can be extended to the entire country \\
\hline
\end{tabular}

\section{Conclusions and recommendations}

This study has developed a collaborative information integration framework and a

701 prototype system for collecting, analyzing, and disseminating safety information

702 among all stakeholders in a construction project. The proposed framework has

703 addressed current practices of site safety inspections that suffer heavily from issues with

704 paper-based recording and information asymmetry. A prototype implementation of the 
framework was tested and validated in a case study. The prototype system was accepted by the industry stakeholders because it offered powerful assistance to manual safety inspection using a standard hazard database and recording template accessible on portable devices, but also utilized various smart sensors to achieve the real-time monitoring of large equipment and facilities. The proposed framework demonstrated great potential to improve the effectiveness of site safety inspection and facilitate the development of collaborative safety management.

Certain limitations remain in the current research. First, the calculation method for risk level in the framework's safety reporting layer needs to be further optimized. Currently, the risk levels are calculated according to the severity score in the standard and the simple assignment of rectification status. More sophisticated methods to quantitatively assess project safety performance using integrated indicators have not yet been incorporated, which is one of the future research directions. Second, the prototype was only evaluated in a trial, it only considered a limited range of stakeholders: local government, service provider, and general contractors. However, more effective management requires a larger scope of collaboration, so other project stakeholders in the construction industry should be included, such as owners, project managers, engineers, and site supervisors. These parties would contribute to the data input into the system and also receive valuable safety information for their own operations and management. Third, the promotion of the system should follow a gradual path. In the current market, construction safety awareness has yet to be improved and commercial insurance coverage is low. As a result, service providers should first seek the cooperation of the government to accomplish top-down reform. Possible ways to accomplish this, such as government purchase of third-party services, can be adopted to solve the problems of information asymmetry and inefficient communication. Finally, only a limited number of projects in a single city was included in the case study of the proposed framework and prototype. Future studies should test the prototype with more cases to determine and compare the quantitative effects in different project situations.

\section{Acknowledgements}

We acknowledge the financial support of the Natural Science Foundation of China (No. 51878382 \& No. 51578317) and Construction Safety Assessment (No. 20172000765). We are also grateful for input from the industry professionals who participated in this 
research: Hui YU, Ning ZHANG, and Ruiqiang WANG.

Declarations of interest: None.

\section{References}

[1] OHSAS 18002:2008 Occupational health and safety management systems Guidelines for the implementation of OHSAS 18001:2007, (2008). British Standards Institution. https://shop.bsigroup.com/ProductDetail/?pid=000000000030176336

[2] Construction Project Safety Production Management Regulations, (2003). The State Council of the People's Republic of China. http://www.gov.cn/gongbao/content/2004/content_63050.htm

[3] Zhang, H., Chi, S., Yang, J., Nepal, M., \& Moon, S. (2016). Development of a safety inspection framework on construction sites using mobile computing. Journal of Management in Engineering, 33(3), 04016048. doi: https://doi.org/10.1061/(ASCE)ME.1943-5479.0000495

[4] Gunduz, M., \& Laitinen, H. (2018). Observation based safety performance indexing method for construction industry - validation with SMEs. Ksce Journal of Civil Engineering, 22(2), 440-446. doi:10.1007/s12205-017-1589-3

[5] Cheung, W. F., Lin, T. H., \& Lin, Y. C. (2018). A real-time construction safety monitoring system for hazardous gas integrating wireless sensor network and building information modeling technologies. Sensors (Switzerland), 18(2). doi:10.3390/s18020436

[6] Khanzode, V. V., Maiti, J., \& Ray, P. K. (2012). Occupational injury and accident research: A comprehensive review. Safety Science, 50(5), 1355-1367. doi:https://doi.org/10.1016/j.ssci.2011.12.015

[7] Albert, A., Hallowell, M. R., \& Kleiner, B. M. (2014). Experimental field testing of a real-time construction hazard identification and transmission technique. Construction Management and Economics, 32(10), 1000-1016. doi:10.1080/01446193.2014.929721

[8] Gainet, C. (2011). Exploring the Impact of Legal Systems and Financial Structure on Corporate Responsibility. Journal of Business Ethics, 95(2), 195. doi:10.1007/s10551-011-0854-5

[9] Campbell, J. L. (2007). Why would corporations behave in socially responsible 
ways? An institutional theory of corporate social responsibility. The Academy of Management Review, 32(3), 946-967. doi:10.2307/20159343

[10]Tam, C. M., Zeng, S. X., \& Deng, Z. M. (2004). Identifying elements of poor construction safety management in China. Safety Science, 42(7), 569-586. doi:https://doi.org/10.1016/j.ssci.2003.09.001

[11]Bai, P., Liu, X., \& Zhang, L. (2015). Preliminary Study on the Safety Management Mode of the Third Party in Engineering Construction. Construction Economy, 36(10), 48-51. doi: 10.14181/j.cnki.1002-851x.201510048

[12]Zhang, R., Zhou, Y., Zhuang, H., \& Zhu, X. (2015). Study on the project supervision system based on the principal-agent theory. Journal of Industrial Engineering and Management, 8(2), 491. doi: http://dx.doi.org/10.3926/jiem.1328

[13]Mei, T., Wang, Q., Xiao, Y., \& Yang, M. (2017). Rent-seeking behavior of BIM \& IPD-based construction project in china. Engineering Construction \& Architectural Management, 24(3). doi: 10.1108/ECAM-11-2015-0178

[14]Cheng, G., Wang, X. Jing, Y., \& Guan, X. (2016). The engineering insurance mechanism based on third party security institutions. Shanghai Management Science, 38(01), 86-88. doi:10.3969/j.issn.1005-9679.2016.01.015

[15]Yang, J. (2017). Optimization of construction project quality insurance model. Supervision Test and Cost of Construction, 10(04), 32-34. http://kns.cnki.net/KCMS/detail/detail.aspx?dbcode=CJFQ\&dbname=CJFDLAS T2017\&filename=PJZJ201704010\&uid=WEEvREcwSIJHSldRa1FhcEE0RVZyc GVIa1lUK3NrcFh3YllGdUFiM3RLMD0=\$9A4hF_YAuvQ5obgVAqNKPCYcEj KensW4ggI8Fm4gTkoUKaID8j8gFw!!\&v=Mjk5MTdXTTFGckNVUkxLZ11IUn ZGeUhuVXI3T05TZIJaTEc0SDliTXE0OUVaSVI4ZVgxTHV4WVM3RGgxVD $\mathrm{NxVHI}=$

[16]Zhao, T., Liu, W., Jiang, L., \& Yuan, K. (2017). Research on the Third Party Safety Supervision Service Pattern of Construction Projects. Industrial Safety and Environmental Protection, 43(01), 84-87. doi:10.3969/j.issn.1001425X.2017.01.024

[17]Xu, Y., \& Li, S. (2010). Economic analysis on the behavior of engineering supervision rent-seeking. Technological Development of Enterprise, 29(15), 151153. doi: $10.14165 /$ j.cnki.hunansci.2010.15.066

[18]Lin, Y. C., Su, Y. C., Lo, N. H., \& Chen, W. F. C. A. (2013). Application of mobile RFID-based safety inspection management at construction jobsite. Radio 
Frequency Identification from System to Applications. doi: http://dx.doi.org/10.5772/53176

[19]Hou, L., Wang, X., Bernold, L., \& Love, P. E. (2013). Using animated augmented reality to cognitively guide assembly. Journal of Computing in Civil Engineering, 27(5), 439-451. doi: https://doi.org/10.1061/(ASCE)CP.1943-5487.0000184

[20] Teizer, J. (2016). Right-time vs real-time pro-active construction safety and health system architecture. Construction Innovation, 16(3), 253-280. doi: https://doi.org/10.1108/CI-10-2015-0049

[21]Zhou, C., \& Ding, L. Y. (2017). Safety barrier warning system for underground construction sites using internet-of-things technologies. Automation in Construction, 83. doi: http://dx.doi.org/10.1016/j.autcon.2017.07.005

[22] Carbonari, A., Giretti, A., \& Naticchia, B. (2011). A proactive system for realtime safety management in construction sites. Automation in Construction, 20(6), 686-698. doi:https://doi.org/10.1016/j.autcon.2011.04.019

[23]Park, J., Yang, X., Cho, Y. K., \& Seo, J. (2017). Improving dynamic proximity sensing and processing for smart work-zone safety. Automation in Construction, 84, 111-120. doi:https://doi.org/10.1016/j.autcon.2017.08.025

[24]Costin, A., Pradhananga, N., \& Teizer, J. (2012). Leveraging passive RFID technology for construction resource field mobility and status monitoring in a high-rise renovation project. Automation in Construction, 24, 1-15. doi:https://doi.org/10.1016/j.autcon.2012.02.015

[25]Lee, U.-K., Kim, J.-H., Cho, H., \& Kang, K.-I. (2009). Development of a mobile safety monitoring system for construction sites. Automation in Construction, 18(3), 258-264. doi:https://doi.org/10.1016/j.autcon.2008.08.002

[26] Naticchia, B., Vaccarini, M., \& Carbonari, A. (2013). A monitoring system for real-time interference control on large construction sites. Automation in Construction, 29, 148-160. doi:https://doi.org/10.1016/j.autcon.2012.09.016

[27]Xiang, P., Huo, X., \& Shen, L. (2015). Research on the phenomenon of asymmetric information in construction projects - The case of China. International Journal of Project Management, 33(3), 589-598. doi:https://doi.org/10.1016/j.ijproman.2014.10.007

[28]Ceric, A. (2013). Application of the principal-agent theory to construction managment: literature review. Paper presented at the 29th Association of Researchers in Construction Management, United Kingdom. ISBN: 978-0- 
9552390-7-6.

http://pdfs.semanticscholar.org/6355/03c8bd18f98020a6498c30695898d202959d. pdf

[29]Zhang, D. Q., \& Guan, K. (2000). Study on information model of construction industry and asymmetric information. Journal of Harbin University of Civil

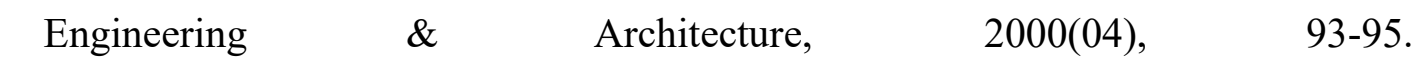
http://kns.cnki.net/KCMS/detail/detail.aspx?dbcode=CJFQ \&dbname=CJFD2000 \&filename=HEBJ200004024\&uid=WEEvREcwSIJHSldRa1FhcEE0RVZycGVIa 11UK3NrcFh3Y11GdUFiM3RLMD0=\$9A4hF_YAuvQ5obgVAqNKPCYcEjKens W4ggI8Fm4gTkoUKaID8j8gFw!!\&v=MjY0NjRaTEc0SHRITXE0OUhZSVI4Z VgxTHV4WVM3RGgxVDNxVHJXTTFGckNVUkxLZ1llUnZGeUhtVzczSkxTa $\mathrm{ko}=$

[30]Turner, J. R., \& Müller, R. (2004). Communication and Co-operation on Projects Between the Project Owner As Principal and the Project Manager as Agent. European Management Journal, 22(3), 327-336. doi:https://doi.org/10.1016/j.emj.2004.04.010

[31]Xiang, P., Zhou, J., Zhou, X., \& Ye, K. (2012). Construction project risk management based on the view of asymmetric information. Journal of Construction Engineering \& Management, 138(11), 1303-1311. doi: https://doi.org/10.1061/(ASCE)CO.1943-7862.0000548

[32]Ceric, A. (2012). Communication risk in contruction projects: application of principal-agent theory. Organization Technology \& Management in Construction, 4(2), 522-533. doi: 10.5592/otmcj.2012.2.8

[33]Ceric, A. (2012). Communication risk in contruction projects: application of principal-agent theory. Organization Technology \& Management in Construction, 4(2), 522-533. doi: 10.5592/otmcj.2012.2.8

[34]Liu, J., Li, B., Lin, B., \& Nguyen, V. (2007). Key issues and challenges of risk management and insurance in china's construction industry: an empirical study. Industrial Management \& Data Systems, 107(3), 382-396. doi: https://doi.org/10.1108/02635570710734280

[35]Zhao, T., Hu, S., \& Zhou, W. (2008). Accident prevention system of construction contingency insurance. China Civil Engineering Journal, 2008(10), 106-110. doi: 10.15951/j.tmgcxb.2008.10.017

[36]Musundire, S., \& Aigbavboa, C. (2015). Management of construction risk through 
contractor's all risk insurance policy : a South Africa case study. Bernard Price Institute for Palaeontological Research, 38, 1-17. doi: 10.14288/1.0076338

[37]Chen, Z., \& Hu, Z. (2012). Insurance ratemaking method for risk of construction diversion project. Engineering Sciences, 10(2), 90-96. http://kns.cnki.net/KCMS/detail/detail.aspx?dbcode=CJFQ\&dbname=CJFD2012 \&filename=ENSC201202014\&uid=WEEvREcwS1JHSldRa1FhcEE0RVZycGVIa 11UK3NrcFh3Y11GdUFiM3RLMD0=\$9A4hF_YAuvQ5obgVAqNKPCYcEjKens W4ggI8Fm4gTkoUKaID8j8gFw!!\&v=MDE0MjZLZ111UnZGeUhuVUwvT01DU FliYkc0SD1QTXJZOUVZSVI4ZVgxTHV4WVM3RGgxVDNxVHJXTTFGckN VUkw=

[38]Zhang, S., Meng, J., \& Zhao, L. M. (2016). Analysis to engineering quality insurance and its ratemaking problem. Value Engineering, 35(27), 229-231. doi: 10.14018/j.cnki.cn13-1085/n.2016.27.096

[39] Schieg, M. (2008). Strategies for avoiding asymmetric information in construction project management. Journal of Business Economics and Management, 9(1), 4751. doi:10.3846/1611-1699.2008.9.47-51

[40]Bond-Barnard, T. J., Steyn, H., \& Fabris-Rotelli, I. (2013). The impact of a call centre on communication in a programme and its projects. International Journal of Project Management, 31(7), 1006-1016. doi:https://doi.org/10.1016/j.ijproman.2012.12.012

[41] Sunkara, P. (2005). A tablet PC application for construction site safety inspection and fatality prevention. Louisiana State University in Shreveport, Retrieved from http://etd.lsu.edu/docs/available/etd-08222005160304/unrestricted/Sunkara_thesis.pdf

[42]Kang, S. C., Lin, K. Y., \& Tsai, M. H. (2011). The Development of an Innovative Tool Kit to Support Construction Safety Audits. Paper presented at the International Council for Research and Innovation in Building and Construction (CIB 099), Washington, D.C., USA. http://www.irbnet.de/daten/iconda/CIB_DC24275.pdf

[43]Kelm, A., Laußat, L., Meins-Becker, A., Platz, D., Khazaee, M. J., Costin, A. M., . . . Teizer, J. (2013). Mobile passive Radio Frequency Identification (RFID) portal for automated and rapid control of Personal Protective Equipment (PPE) on construction sites. Automation in Construction, 36, 38-52. doi:https://doi.org/10.1016/j.autcon.2013.08.009 
[44]Dong, S., Li, H., \& Yin, Q. (2018). Building information modeling in combination with real time location systems and sensors for safety performance enhancement. Safety Science, 102, 226-237. doi: 10.1016/j.ssci.2017.10.011

[45]Seo, J., Han, S., Lee, S., \& Kim, H. (2015). Computer vision techniques for construction safety and health monitoring. Advanced Engineering Informatics, 29(2), 239-251. doi:https://doi.org/10.1016/j.aei.2015.02.001

[46]Han, Y., Zhang, J., Sun, H., Yao, J., \& You, S. (2016). Design and implementation of intelligent safety inspection system for construction workers based on image recognition. Journal of Safety Science and Technology, 12(10), 142-148. doi:10.11731/j.issn.1673-193x.2016.10.024

[47] Starbuck, R., Seo, J. O., Han, S. U., \& Lee, S. H. (2014). A Stereo Vision-Based Approach to Marker-Less Motion Capture for On-Site Kinematic Modeling of Construction Worker Tasks. International Conference on Computing in Civil and Building Engineering. doi: https://doi.org/10.1061/9780784413616.136

[48]Escorcia, V., Dávila, M. A., Golparvar-Fard, M., \& Niebles, J. C. (2012). Automated vision-based recognition of construction worker actions for building interior construction operations using RGBD cameras. Paper presented at the Construction Research Congress 2012: Construction Challenges in a Flat World, Proceedings of the 2012 Construction Research Congress. doi: 10.1061/9780784412329.089

[49]Tsai, Y. H., Hsieh, S. H., \& Kang, S. C. (2014). A BIM-Enabled Approach for Construction Inspection. International Conference on Computing in Civil and Building Engineering (pp.721-728). doi: https://doi.org/10.1061/9780784413616.090

[50]Costin, A. M., Teizer, J., \& Schoner, B. (2015). RFID and BIM-enabled worker location tracking to support real-time building protocol and data visualization. Journal of Information Technology in Construction (ITcon), 20(29), 495-517. https://www.itcon.org/papers/2015_29.content.08252.pdf

[51]Lin, K.-Y., Tsai, M.-H., Gatti, U. C., Je-Chian Lin, J., Lee, C.-H., \& Kang, S.-C. (2014). A user-centered information and communication technology (ICT) tool to improve safety inspections. Automation in Construction, 48, 53-63. doi:https://doi.org/10.1016/j.autcon.2014.08.012

[52]Ding, L. Y., Zhou, C., Deng, Q. X., Luo, H. B., Ye, X. W., Ni, Y. Q., \& Guo, P. (2013). Real-time safety early warning system for cross passage construction in 
Yangtze Riverbed Metro Tunnel based on the internet of things. Automation in Construction, 36, 25-37. doi:https://doi.org/10.1016/j.autcon.2013.08.017

[53] Standard for Construction Safety Inspection JGJ59-2011, (2011). Ministry of Housing and Urban-Rural Construction of the People's Republic of China. http://www.ccsn.gov.cn/Xxbz/ShowForceStandard.aspx?Guid=f25fef5d-bb324190-b3c7-cd71be5ef45d 